Rabaska

Revue d'ethnologie de l'Amérique française

CADRIN, GASTON. Les Excommuniés de

Saint-Michel-de-Bellechasse au XVIII ${ }^{e}$ siècle. Québec, Les

Éditions GID, 2015, 405 p. ISBN 978-2-89634-271-6

\title{
Jacques Saint-Pierre
}

Volume 16, 2018

URI : https://id.erudit.org/iderudit/1051345ar

DOI : https://doi.org/10.7202/1051345ar

Aller au sommaire du numéro

Éditeur(s)

Société québécoise d'ethnologie

ISSN

1703-7433 (imprimé)

1916-7350 (numérique)

Découvrir la revue

Citer ce compte rendu

Saint-Pierre, J. (2018). Compte rendu de [CADRIN, GASTON. Les Excommuniés de Saint-Michel-de-Bellechasse au XVIII ${ }^{e}$ siècle. Québec, Les Éditions GID, 2015,

405 p. ISBN 978-2-89634-271-6]. Rabaska, 16, 250-252.

https://doi.org/10.7202/1051345ar d'utilisation que vous pouvez consulter en ligne.

https://apropos.erudit.org/fr/usagers/politique-dutilisation/ 
de ceux s'adressant aux garçons. Pendant que les petites filles jouaient à la maîtresse d'école (brosse à tableau, tableau, boulier compteur), à la coiffeuse, à la secrétaire, à la téléphoniste ou à l'infirmière, les petits garçons rêvaient de devenir commerçant, menuisier, fermier, garagiste, pompier ou médecin.

Ces ouvrages nous permettent d'autre part de réaliser à quel point les jouets étaient encore à cette époque un luxe auquel tous les enfants n'avaient pas accès. Même s'il existait déjà une grande quantité de jeux et de jouets fabriqués industriellement, il n'était pas rare que les enfants provenant de familles nombreuses et moins fortunées n'aient pas autre chose pour s'amuser que de découper dans les catalogues, empiler des bâtons de popsicle, ou encore classer des boutons par couleur. Certains témoignages recueillis par Jean Bouchard auprès de personnes qui ont grandi à cette époque et qui n'ont pas eu la chance d'avoir beaucoup de jouets sont d'ailleurs très émouvants.

Les jouets présentés dans ces deux volumes ne sont qu'un aperçu de l'immense collection de Jean Bouchard. En publiant ces livres, il ne fait aucun doute que ce grand collectionneur a atteint le but qu'il s'était fixé : nous replonger dans nos souvenirs d'enfance.

Suzanne Marchand Société québécoise d'ethnologie

CAdrin, Gaston. Les Excommuniés de Saint-Michel-de-Bellechasse au XVIII ${ }^{e}$ siècle. Québec, Les Éditions GID, 2015, 405 p. ISBN 978-2-89634-271-6.

Pendant la décennie 1780, cinq personnes ont été inhumées dans un cimetière privé situé sur la terre de Pierre Cadrin au quatrième rang de SaintMichel-de-Bellechasse. Cette terre se trouve aujourd'hui dans les limites de la municipalité de La Durantaye. Les cadavres ont été exhumés un siècle plus tard, ce qui a inspiré à Louis Fréchette son poème « Les Excommuniés ». En 1977, Raoul Roy, un militant indépendantiste reconnu, a publié une brochure sur la question, sous le titre Patriotes indomptables de La Durantaye. Gaston Cadrin explique que ce dernier lui a remis une copie de son travail, ce qui l'a incité, plusieurs années plus tard, à fouiller le sujet lui-même.

La validation de l'identité des " excommuniés » est le point de départ d'une reconstitution des familles des cinq personnes auxquelles le poème de Louis Fréchette fait référence. Le choix du titre du livre ne donne pas la mesure de l'ampleur de la recherche effectuée par Gaston Cadrin, qui décrit, en fait, la vie des colons dans la plaine côtière de Bellechasse au XVIII ${ }^{\mathrm{e}}$ siècle.

Les quatre premiers chapitres retracent la généalogie de la famille Cadrin et des familles qui lui sont alliées par le mariage ou le voisinage. Le « clan de la côte Saint-René » ou du quatrième rang apparaît tissé serré, les alliances 
matrimoniales se concluant très souvent dans un cercle étroit, ce qui renforce la solidarité. Il n'est évidemment pas facile de décrire la vie de ces colons du $\mathrm{XVIII}{ }^{\mathrm{e}}$ siècle à partir de documents notariés et des registres d'état civil. L'auteur tire cependant le maximum de ces documents et parvient à reconstituer le cadre matériel de la vie des habitants et les grandes étapes du cycle familial (formation du couple, naissance des enfants, mortalité infantile, évolution des biens fonciers, dispositions successorales, transmission du patrimoine). Les mariages sont l'occasion de faire la noce et l'on ne s'en privait pas, selon Cadrin, même dans les petites maisons des colons. Ici, l'auteur doit combler les lacunes de la documentation en s'en remettant à ce que des gens comme Nicolas-Gaspard Boisseau ont écrit sur le mariage auX XVII et XVIII ${ }^{\mathrm{e}}$ siècles. Du moins, c'est ce qu'il faut supposer !

Les cinq chapitres suivants portent sur les tensions coloniales, le siège de Québec et le régime militaire. Les faits relatés sont connus, mais ils sont observés dans le cadre d'une région, soit la partie ouest de la Côte-du-Sud, qui a été aux premières loges durant l'invasion de 1759. Cette section du livre est événementielle. Les dévastations des troupes de Wolfe, les déplacements de la population vers l'intérieur des terres, la mobilisation des miliciens, la pendaison du meunier Joseph Nadeau et l'épisode de la Corriveau sont relatés pour comprendre le climat général dans lequel évoluent les familles des « rebelles » de 1775. Cadrin croit que le souvenir de ces événements tragiques a influencé le comportement des « excommuniés » de Saint-Michel.

Les trois chapitres suivants couvrent la fin du régime militaire, le retour progressif à la normale après la signature du traité de Paris (1763), l'invasion américaine et l'attitude ambivalente des habitants de la région face à celle-ci (qui donne lieu à un affrontement sanglant à Saint-Pierre, sur les bords de la rivière du Sud), l'échec des Américains et les représailles des autorités. C'est ici que se situe l'incident ayant mené à la supposée excommunication de Pierre Cadrin. Celui-ci aurait osé lancer, durant le sermon d'un père jésuite venu inciter les paroissiens à rester fidèles à la Couronne britannique : «C'est trop longtemps prêcher pour les Anglais ! Informé de cet affront, l'évêque Briand a alors demandé au curé de Saint-Michel de lui transmettre le nom de l'auteur de cette insolence ou, à défaut de pouvoir le faire, il jettera l'interdit sur la paroisse. On sait que l'église de Saint-Michel a ensuite été fermée durant un mois. Quant à Pierre Cadrin, qui était âgé de 75 ans, il n'était pas présent à l'église lors de la plupart des baptêmes, mariages et funérailles des membres de sa famille ou des voisins célébrés ultérieurement. On n'a cependant retrouvé aucune sentence d'excommunication.

L'avant-dernier chapitre est consacré aux circonstances des décès de Pierre Cadrin et des autres personnes inhumées dans le cimetière privé. Le seul fait avéré est l'inhumation de Pierre Cadrin sur sa terre ; il serait décédé 
entre 1781 et 1783 . Le dernier chapitre porte sur l'exhumation, le 11 octobre 1880 , des restes des cinq personnes et leur réinhumation dans la partie du cimetière paroissial réservée aux enfants morts sans avoir reçu le baptême. En épilogue, l'auteur résume le fruit de sa longue enquête qui s'est échelonnée sur cinq ans.

Gaston Cadrin démontre qu'en partant d'une démarche généalogique, il est possible d'élargir le champ d'investigation pour rejoindre l'histoire sociale. L'ouvrage jette notamment un éclairage sur un aspect méconnu de la vie rurale au XVIII ${ }^{\mathrm{e}}$ siècle, soit le voisinage. Les familles auxquelles appartiennent les « excommuniés» sont des voisins et elles entretiennent des liens étroits. Leur cimetière aurait d'ailleurs pu devenir l'embryon d'une nouvelle communauté paroissiale.

Si l'on en juge par la bibliographie du livre, l'auteur n'a pas tenu compte des nombreuses études qui ont été faites depuis les années 1980 sur les pratiques religieuses, le choix des conjoints, les stratégies familiales, la reproduction sociale, la gestion des seigneuries, l'occupation et la mise en valeur du territoire $\mathrm{au} \mathrm{XVIII}{ }^{\mathrm{e}}$ siècle. Cela lui aurait permis de mieux inscrire sa recherche dans l'historiographie contemporaine et lui aurait facilité l'interprétation de ses propres observations en lui fournissant des points de comparaison utiles.

On aurait souhaité aussi une meilleure présentation des sources documentaires, en particulier des archives paroissiales et diocésaines consultées. L'auteur cite aussi souvent la tradition orale, sans que l'on sache toujours à quoi il se réfère : souvenirs transmis dans sa famille, enquêtes personnelles ou par d'autres chercheurs auprès d'informateurs identifiés, tradition ancienne consignée dans des textes écrits (œuvres littéraires, journaux, monographies paroissiales, etc.). Certaines sont identifiées en partie dans les notes, mais il aurait été utile de les reprendre dans la bibliographie en une section portant spécifiquement sur cette tradition orale.

Le livre est un ouvrage d'érudition, mais aussi de vulgarisation. Il est abondamment illustré et saura plaire à un large public intéressé par la vie en Nouvelle-France et au début du Régime anglais.

Jacques SAint-Pierre Historien, Québec

Cloutier, Jean et Jean-Pierre Charest. Les Bateaux-phares du Saint-Laurent. En aval de Québec, 1830-1963. Québec, Les Éditions du Septentrion, 2016, 400 p. ISBN 978-2-89448-862-1.

Pan méconnu de l'histoire maritime du Québec, la présence des bateauxphares pour la sécurité de la navigation sur le Saint-Laurent est racontée dans 